\title{
In-silico research of the influence of gas injection into the subsea crude oil pipeline on the paraffin solid phase deposition
}

\author{
Artur Wójcikowski ${ }^{1}$, Stanisław Nagy $^{2}$, \\ ${ }^{1}$ LOTOS PETROBALTIC S.A., 80-758 Gdansk, Poland \\ ${ }^{2}$ AGH University of Science and Technology, 30-059 Cracow, Al. Mickiewicza 30, Poland
}

\begin{abstract}
The aim of the article is presenting of the preliminary results of simulations showing behaviour of paraffin deposits in submarine pipelines. The described parameters for changing the deposition of the solid paraffin phase with the flow of crude oil through the submarine pipeline inside the subsea system: subsea wellhead - platform processing system. The research includes considerations of the behaviour of paraffins in the presence of the injected gas phase. Author recommends using of phenomenon as an alternative way of securing submarine pipelines operating on the Baltic Sea. This analyse informs that the paraffin' deposit is possible to adjust of it's thickness buy using agents other than purely chemical paraffin point temperature depressants. It is supposed here that main impact on paraffin deposition behaviour get decreasing of sediments thickness on the walls of the submarine pipeline in the analysed sections. The reservoir fluid composition used in the simulation was taken from B3 fluid PVT analysis owned by LOTOS Petrobaltic S.A. General composition was used in Leda Flow 2.5 computer analysis in courtesy of Kongsberg Company.
\end{abstract}

\section{Introduction}

Subsea pipelines transport of hydrocarbons has always encountered technical complications leading to failures. One of the most common and dangerous effects is the appearance of a solid phase in the flowing stream, the so-called "deposition" of a solid phase. It often consists of n-alkanes, iso-alkanes, cyclo-alkanes, commonly known as paraffins and waxes. Since many years new methods have been sought to facilitate and improve the flow of hydrocarbons through submarine pipelines. It becomes of one of the most important challenges for the oil industry. For this purpose, it has been proposed to use the available simulation tools illustrating the phenomena occurring during the flow of the hydrocarbon three-phase mixture in the subsea wellhead - pipeline system and on the platform deck.

\subsection{The behaviour of paraffin crude oil in submarine pipelines}

One of the most important aspects is the indication of the point of appearance of paraffins in the solid phase and just before that moment. Both moments are identified by the size of the oil temperature and the phenomena that occur. This parameter is the temperature of the appearance of paraffins, waxes WAT (wax appearance temperature). Apart from the temperature and pressure itself, the content of light hydrocarbons is also important [1]. The WAT temperature determines the temperature level at or below which the solid phase of waxes as a mixture of paraffins, naphthene and aromas should be expected to occur.

\subsubsection{B3 crude oil characteristic}

The report [4] also presents the results of the analysis of B3 oilfield crude oil sample, based on the following standards IS-16 / KE and IR-7 / KE and test procedures (PN-C 04105: 1990) for temperature of the paraffin point adjustment and the percentage of paraffins were determined, respectively, [Table 1.]

Table 1. Results of the chemical analysis of paraffin determination in tested crude oil

\begin{tabular}{|c|c|c|}
\hline Parameters & Unit & $\begin{array}{c}\text { Indicated } \\
\text { results }\end{array}$ \\
\hline WAT & {$\left[{ }^{\circ} \mathrm{C}\right]$} & 21,6 \\
\hline Paraffins & {$[\% \mathrm{wt}]$} & 2,15 \\
\hline
\end{tabular}

Properties of crude oil from the B3 field [4];

- Bottom hole pressure $\mathrm{P}=152.8$ [bar],

- Bottom hole temperature $\mathrm{T}=62\left[{ }^{\circ} \mathrm{C}\right]$,

- Saturation pressure 84 [bar],

- Crude oil volume coefficient $1.411\left[\mathrm{~m}^{3} / \mathrm{m}^{3}\right]$,

- Gas solubility Rs $=116.7\left[\mathrm{~m}^{3} / \mathrm{m}^{3}\right]$.

Based on the obtained results, it was confirmed that there is a risk of paraffin deposition under the separation conditions also in the infrastructure elements of the B3 field [4]. Light hydrocarbons evaporate in a separation process that reduces the pressure below the saturation pressure. As indicated in [2], measurements performed 
on surface samples often lead to false measurements in the matter of solid phase presence. This fact created the concept of using light hydrocarbon fractions to lower WAT

\subsection{Simulation model characteristic}

The On Fig. 4. phase diagram obtained from the performed PVT simulation has been showed. Compared with the values present at the sea bottom, we can expect deposition of paraffins in the offshore pipeline.

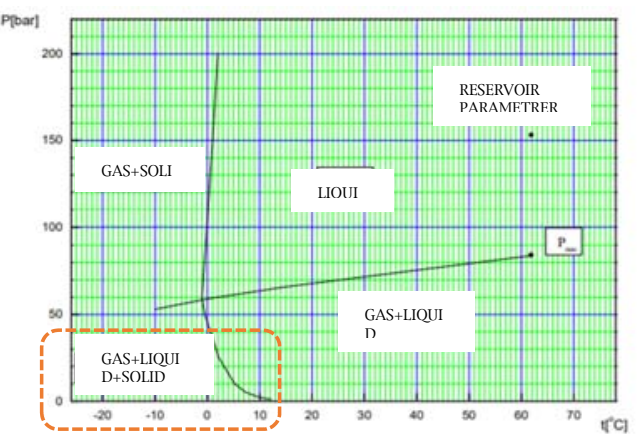

Fig.4. B3 crude oil sample phase diagram with indication of production parameters range [4]

As a one of the results of the performed analyses, it was found that the beneficial effect on oil production conditions will be reversal of gas separation process, by use of artificial supply of loosed gas from the transported crude oil. This reversal process may result of solid phase deposition point shifting to the place where heating or minor chemical WAT depressants can be applied in reduced amounts. Taking as advantage of this effect, it was proposed to use the capabilities of Kongsberg's 1-D Leda Flow 2.5 simulator [3,5]. The Lee' model is a two-dimensional model, which in LedaFlow has been limited to one dimension, not losing much of its accuracy, while gaining high computational efficiency.

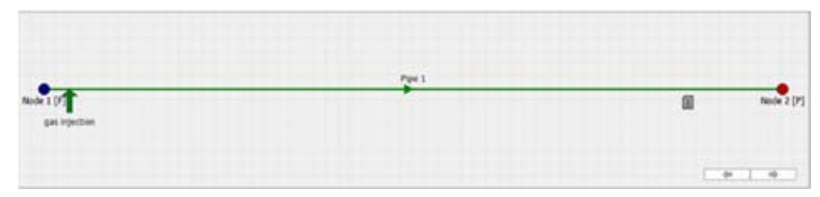

Fig. 5. Model of the oil transport system used in the simulator, oil flow direction from the underwater head (Node 1) to the platform (Node 2).

\subsection{Simulation' results discussion}

The obtained information of deposition in the conditions of undisturbed flow [Fig. 6-B] in the first 40000 seconds indicates a quick cooling of the crude oil after the oil exits the head and achieving the WAT temperature by the crude.

The next stage was the injection of single-component gas $(\mathrm{C} 5+)$ at the theoretical injection point location at $50 \mathrm{~m}$ from the subsea wellhead. The nature of the curve obtained, observed already after 35000 seconds, is different from the variant without injection. Although the crude oil is cooled more intensively, attention should be paid to the intensity of deposition. By the time of 35 000 seconds of simulation (Fig. 7D), the amount of deposition is twice as small as in the variant without gas injection. Maintaining the deposit thickness at $0.02 \mathrm{~mm}$. The obtained simulation results are an incentive for further analyses of additional modification of the input parameters. In this approach, gas injection was a new element, which apparently caused quite significant changes. In further simulations, with similar results will be obtained, it is assumed that the use of gas injection as a neutral and available would contribute to the creation of another alternative way of securing the operation of subsea pipelines.

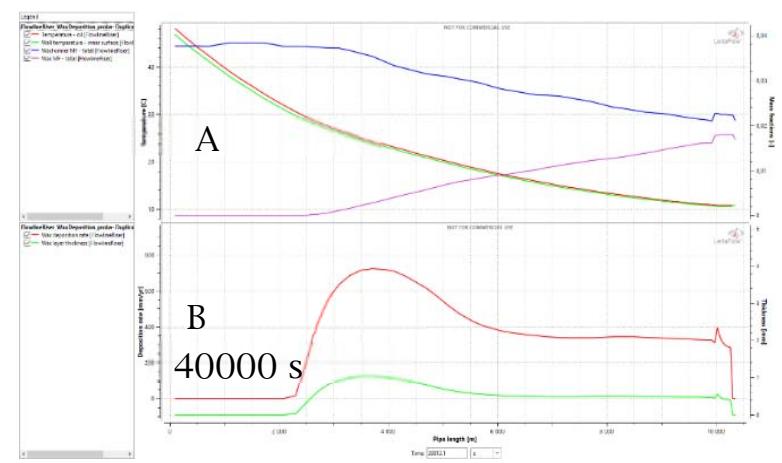

Fig. 6. The graphs show undisturbed paraffin deposition, the immediate increase corresponds to the WAT temperature (simulation time 40,000s).

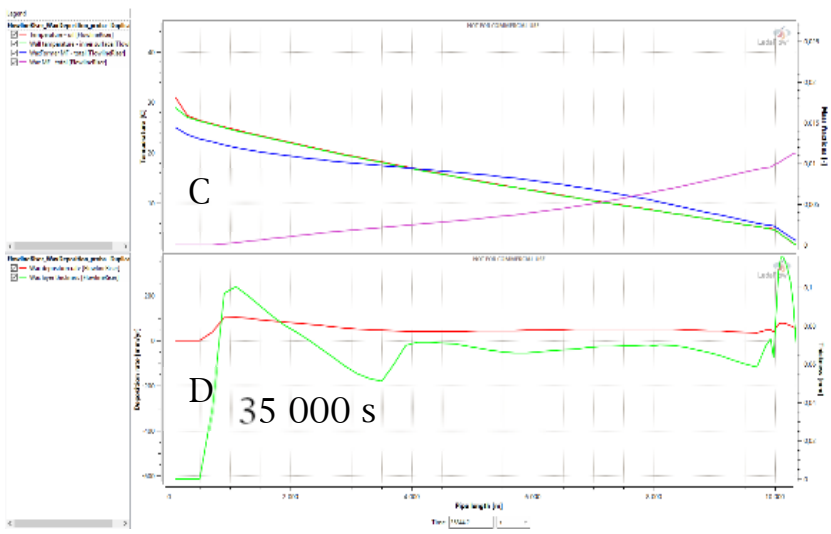

Fig. 7. The graphs show the behaviour of the paraffin deposition profile, introducing disturbances by gas injection into the deposit phenomena change the profile and trend (simulation time $35,000 \mathrm{~s}$ )

\subsection{References}

1. Zhu T., Walker J.A. et al., F. Rep. Pet. Dev. Lab., Univ. of Alaska, Fairbanks, 2005

2. Zhenyu H. Sheng Zheng, H. Scott Fogler., CRC Press 2016, e-Book ISBN 9780429099410

3. Hyun Su Lee, PhD dissert., The University of Michigan, 2008

4. Bęben D., Korpanty W. INiG Kraków, Oddział Krosno, 2009,

5. LedaFlow 1D, 2.5. Kongsberg Digital, Norway 2019 